\title{
Long-term Outcomes after the Discontinuation of Anti-Tumor Necrosis Factor-a Therapy in Patients with Inflammatory Bowel Disease under Clinical Remission: A Korean Association for the Study of Intestinal Disease Multicenter Study
}

\author{
Joo Hye Song1, Eun Ae Kang², Soo-Kyung Park ${ }^{3}$, Sung Noh Hong1', You Sun Kim4, Ki Bae Bang ${ }^{5}$, Kyeong Ok \\ $\mathrm{Kim}^{6}$, Hong Sub Lee ${ }^{7}$, Sang-Bum Kang ${ }^{8}$, Seung Yong Shin ${ }^{9}$, Eun Mi Song ${ }^{10}$, Jong Pil Im ${ }^{11}$, and Chang Hwan Choi ${ }^{9}$, \\ IBD Research Group of the Korean Association for the Study of Intestinal Diseases

\begin{abstract}
${ }^{1}$ Department of Medicine, Samsung Medical Center, Sungkyunkwan University School of Medicine, ${ }^{2}$ Department of Internal Medicine and Institute of Gastroenterology, Yonsei University College of Medicine, ${ }^{3}$ Department of Internal Medicine, Kangbuk Samsung of Medicine, Seoul, ${ }^{5}$ Department of Internal Medicine, Dankook University College of Medicine, Cheonan, ${ }^{6}$ Department of Internal Medicine, Yeungnam University College of Medicine, Daegu, ${ }^{7}$ Department of Internal Medicine, Inje University Busan Paik Hospital, Inje University College of Medicine, Busan, ${ }^{8}$ Department of Internal Medicine, Daejeon St. Mary's Hospital, College of Medicine, The Catholic University of Korea, Daejeon, ${ }^{9}$ Department of Internal Medicine, Chung-Ang University College of Medicine, ${ }^{10}$ Department of Internal Medicine, Ewha Womans University Seoul Hospital, Ewha Womans University School of Medicine, and ${ }^{11}$ Department of Internal Medicine and Liver Research Institute, Seoul National University College of Medicine, Seoul, Korea
\end{abstract} \\ Hospital, Sungkyunkwan University School of Medicine, ${ }^{4}$ Department of Internal Medicine, Seoul Paik Hospital, Inje University College
}

See editorial on page 641.

\section{Article Info}

Received July 29, 2020

Revised December 6, 2020

Accepted December 9, 2020

Published online March 26, 2021

Corresponding Author

Sung Noh Hong

ORCID https://orcid.org/0000-0002-4140-3717

E-mail gisnhong@gmail.com

Soo-Kyung Park

ORCID https://orcid.org/0000-0001-8822-9632 E-mail skparkmd@gmail.com

Joo Hye Song and Eun Ae Kang contributed equally to this work as first authors.
Background/Aims: Our study aimed to evaluate the long-term outcomes and risk factors for relapse after anti-tumor necrosis factor (TNF)- $\alpha$ cessation in inflammatory bowel disease (IBD) patients because they are not well established.

Methods: A retrospective multicenter cohort study was conducted involving patients with Crohn's disease (CD) or ulcerative colitis (UC) from 10 referral hospitals in Korea who discontinued firstline anti-TNF therapy after achieving clinical remission.

Results: A total of 109 IBD patients (71 CD and $38 \mathrm{UC}$ ) with a median follow-up duration of 56 months were analyzed. The cumulative relapse rates at 1,3 , and 5 years were $11.3 \%, 46.7 \%$, and $62.5 \%$ for CD patients and $28.9 \%, 45.3 \%$, and $60.9 \%$ for UC patients. Multivariable Cox analysis revealed that discontinuation owing to the clinician's decision was associated with lower risk of relapse (vs patient's preference: hazard ratio [HR], 0.13; 95\% confidence interval [Cl], 0.04 to $0.48 ; p=0.002$ ) and adalimumab use was associated with higher risk of relapse (vs infliximab: $\mathrm{HR}, 4.42 ; 95 \% \mathrm{Cl}, 1.24$ to $17.74 ; \mathrm{p}=0.022$ ) in CD patients. Mucosal healing was associated with lower risk of relapse (vs nonmucosal healing: $\mathrm{HR}, 0.12 ; 95 \% \mathrm{Cl}, 0.02$ to $0.83 ; \mathrm{p}=0.031$ ) in UC patients. Anti-TNF re-induction was provided to 52 patients, and a response was obtained in 50 patients. However, 25 of them discontinued retreatment owing to a loss of response $(n=15)$, the patient's preference $(n=6)$, and other factors $(n=4)$.

Conclusions: More than $60 \%$ of IBD patients in remission under anti-TNF therapy relapsed within 5 years of treatment cessation. Anti-TNF re-induction was effective. However, half of the patients discontinued anti-TNF therapy, and $50 \%$ of these patients discontinued treatment owing to loss of response. (Gut Liver 2021;15:752-762)

Key Words: Inflammatory bowel diseases; Tumor necrosis factor inhibitors; Withholding treatment; Recurrence 


\section{INTRODUCTION}

Anti-tumor necrosis factor (TNF)- $\alpha$, which has revolutionized treatment of inflammatory bowel disease (IBD), induces not only clinical remission but also mucosal healing and maintains improved quality of life and decreased risk of surgery and hospitalization in IBD patients. ${ }^{1-3}$ However, in real-world practice, the discontinuation of antiTNF has been attributed to various factors, including costs, or concerns regarding long-term safety. ${ }^{4}$

Opportunistic infections have become a major safety concern in patients undergoing anti-TNF. ${ }^{5-7}$ The risk of lymphoma has not been decisively associated with antiTNFs; however, malignancy may still be a concern with continued anti-TNF. ${ }^{8}$ In addition, cutaneous reactions and paradoxical immune-mediated complications have been reported. ${ }^{9}$ Furthermore, despite the introduction of biosimilars, high costs of biologics increase the likelihood of discontinuation. Healthcare costs associated with IBD have shifted from hospitalization/surgery towards medication, such as anti-TNF. ${ }^{10}$

A significant number of IBD patients may experience remission or minimal symptoms for $>10$ years after initial presentation, suggesting that the relapsing-remitting course of IBD may allow - at least in some patients - abstinence from medication. ${ }^{11}$ Although several studies have been performed, the long-term outcomes of IBD patients after anti-TNF cessation are unclear. ${ }^{12-18}$ The current data are insufficient to recommend discontinuation of anti-TNF. ${ }^{19-21}$ This study aimed to evaluate the long-term outcomes and risk factors for relapse following discontinuation of antiTNF in IBD patients with remission.

\section{MATERIALS AND METHODS}

\section{Study population}

We conducted a retrospective multicenter cohort study involving patients from 10 referral hospitals of the IBD research group of the Korean Association for the Study of Intestinal Diseases. The inclusion criteria were as follows: (1) Crohn's disease (CD) or ulcerative colitis (UC) treated with first-line anti-TNF maintenance and (2) discontinuation of anti-TNF after achieving clinical remission. The exclusion criteria were as follows: (1) irregular treatment; (2) followup duration $<1$ year after discontinuation of anti-TNF; and (3) unclear reasons for discontinuation of anti-TNF.

The study protocol was approved by the institutional review board of each participating hospital. On January 14, 2019, the institutional review board of Samsung Medical Center provided their approval to conduct this study (IRB number: 2019-01-003-001). The study protocol conformed to the ethical guidelines of the 1975 Declaration of Helsinki as reflected in a prior approval by the institution's human research committee. The requirement for informed consent from patients was waived because only de-identified data routinely collected during hospital visits were used.

\section{Anti-TNF induction and maintenance therapy}

The enrolled patients followed a prespecified schedule of anti-TNF induction and maintenance therapy. Infliximab (IFX; Remicade ${ }^{\circledR}$, Janssen Pharmaceutical, Beerse, Belgium or Remsima ${ }^{\circledR}$, Celltrion, Incheon, Korea) was administered intravenously, as induction, at $5 \mathrm{mg} / \mathrm{kg}$ at 0 , 2 , and 6 weeks; we then administered $5 \mathrm{mg} / \mathrm{kg}$, as maintenance, every 8 weeks. ${ }^{22,23}$ Adalimumab (ADA; Humira ${ }^{\circledR}$, AbbVie Inc., Chicago, IL, USA) was administered as induction with $160 \mathrm{mg}$ followed by $80 \mathrm{mg}$ after 2 weeks via subcutaneous injection followed by maintenance of 40 mg every other week. ${ }^{23,24}$ Patients with subsequent loss of response (LOR) during maintenance, were administered an escalated dose of IFX at $10 \mathrm{mg} / \mathrm{kg}$ every 8 weeks or a weekly ADA injection. ${ }^{25,26}$

\section{Definition of clinical remission, response, and relapse}

Clinical remission was defined as Crohn's Disease Activity Index $<150$ or the absence of fistula in CD or Mayo score of 0-2 or partial Mayo score of 0-1 for UC. Clinical response was defined as a decrease of 70 points in the Crohn's Disease Activity Index for luminal CD, a 50\% decrease in the number of fistulas from baseline for fistulizing CD, or a decrease of $30 \%$ or 3 points in the Mayo score compared to the baseline for UC. Relapse was defined as Crohn's Disease Activity Index $>220$ or new-onset fistula in CD or Mayo score $\geq 6$ and endoscopic subscore $\geq 2$ in UC, requirement for hospitalization/surgery associated with IBD progression, or re-initiation of steroids or biologics.

\section{Outcome measurements}

The laboratory findings, including hemoglobin, albumin, and C-reactive protein levels were measured before discontinuation of anti-TNF. The clinical features, including age at the time of discontinuation, Montreal location (L1, ileum; L2, colon; or L3, ileocolon), behavior (B1, no strictures and no penetration; B2, strictures; or B3, penetration) and perianal modifier (with or without perianal disease) in CD and Montreal disease extent in UC (E1, ulcerative proctitis; E2, left-sided UC; or E3, extensive UC), were retrospectively reviewed. History of intestinal operation, indication for anti-TNF (luminal or fistulizing CD), type of anti-TNF agent (IFX or ADA), duration of anti- 
TNF treatment, reasons for discontinuation of anti-TNF (clinician's decision, patient's preference, intolerance, and other factors), mucosal healing before discontinuation, and concomitant use of immunomodulators after discontinuation were also assessed retrospectively. Mucosal healing was defined as no definite ulceration on endoscopy in CD or Mayo endoscopic score $<2$ in UC. The final disease status and laboratory findings at the time of relapse or at the latest outpatient visit for patients without relapse, were recorded. In addition, the efficacy and safety of retreatment during the follow-up period were assessed in patients with anti-TNF retreatment after relapse.

The primary outcome was the rate of relapse at 1, 2, 3, and 5 years after discontinuation of anti-TNF. The secondary outcomes included risk factors associated with relapse, relapse-free survival after discontinuation of anti-TNF, and efficacy of anti-TNF retreatment.

\section{Statistical analysis}

Continuous variables are expressed as median with interquartile range, while categorical variables are presented as absolute values and percentages. Continuous variables were analyzed using the unpaired Student t-test and MannWhitney $U$ test, while categorical variables were analyzed using the chi-square test and Fisher exact test. Using the Cox hazards model, the risk factors for relapse after antiTNF cessation were investigated. The survival curve representing the cumulative rate of relapse after discontinuation of anti-TNF was analyzed using the Kaplan-Meier method.
A p-value $<0.05$ was considered statistically significant. All statistical analyses were performed using SPSS software version 25.0 for Windows (SPSS Inc., Chicago, IL, USA).

\section{RESULTS}

\section{Baseline characteristics of the enrolled patients}

A total of 125 IBD patients were eligible for this study. Sixteen patients were excluded as their follow-up period was $<1$ year. A total of 109 IBD patients (71 CD and 38 UC) were eventually analyzed (Fig. 1). The baseline characteristics of the patients are shown in Table 1. Most patients were aged $\leq 40$ years at diagnosis. A greater number of $\mathrm{CD}$ patients discontinued anti-TNF $\leq 40$ years compared to UC patients $(\mathrm{p}<0.001)$. Eighteen CD patients $(25.4 \%)$ had a history of intestinal surgery and $28 \mathrm{CD}$ patients (39.4\%) were treated with anti-TNF for fistulizing. Ninetythree IBD patients $(85.3 \%)$ were treated with IFX. The median duration of anti-TNF before discontinuation was 12.0 months (range, 9.0 to 26.5 months), and the duration between treatment with IFX and ADA were not significantly different (12.0 months [ 10.0 to 27.0 ] vs 12 months [5.0 to 21.5]). The most common factors underlying discontinuation of anti-TNF were clinician's decision (29.4\%) and patient's preference (27.5\%). Among UC patients, $28.9 \%$ of them discontinued anti-TNF owing to intolerance to adverse events (AEs), while $23.9 \%$ of the CD patients discontinued treatment owing to insurance/reimbursement

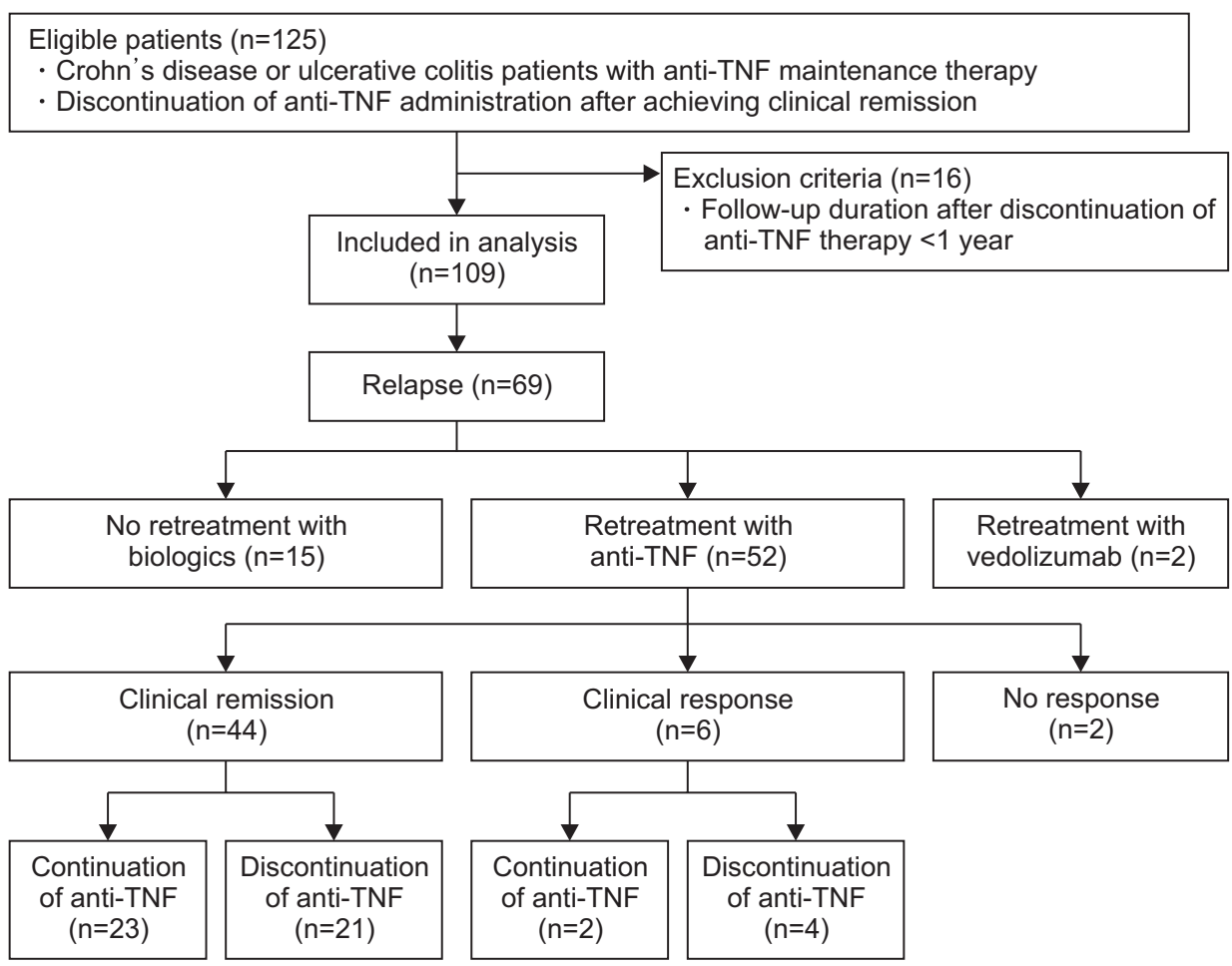

Eligible patients $(n=125)$

- Crohn's disease or ulcerative colitis patients with anti-TNF maintenance therapy

Fig. 1. Flowchart outlining the study protocol. TNF, tumor necrosis factor. 
Table 1. Baseline Characteristics of the Enrolled Patients

\begin{tabular}{|c|c|c|c|c|c|}
\hline \multicolumn{2}{|l|}{ Characteristics } & \multirow{2}{*}{$\begin{array}{l}\text { Total }(n=109) \\
73(67.0)\end{array}$} & \multirow{2}{*}{$\frac{C D(n=71)}{50(70.4)}$} & \multirow{2}{*}{$\frac{U C(n=38)}{23(60.5)}$} & \multirow{2}{*}{$\frac{p \text {-value* }}{0.295}$} \\
\hline Sex & Male & & & & \\
\hline & Female & $36(33.0)$ & $21(29.6)$ & 15 (39.5) & \\
\hline \multirow[t]{3}{*}{ Age at diagnosis, yr } & Median (IQR) & $26.0(20.0-37.0)$ & $23.0(19.0-29.0)$ & $38.0(26.0-48.3)$ & $<0.001$ \\
\hline & $\leq 40$ & $88(80.7)$ & $67(94.4)$ & $21(55.3)$ & $<0.001$ \\
\hline & $>40$ & 21 (19.3) & $4(5.6)$ & $17(44.7)$ & \\
\hline \multirow{3}{*}{$\begin{array}{l}\text { Age at the time of discontinuation of anti-TNF } \\
\text { therapy, yr }\end{array}$} & Median (IQR) & $31.7(24.9-43.0)$ & $28.0(22.0-34.1)$ & $44.0(33.0-58.0)$ & $<0.001$ \\
\hline & $\leq 40$ & $77(74.0)$ & $63(88.7)$ & $14(36.8)$ & $<0.001$ \\
\hline & $>40$ & $32(26.0)$ & 8 (11.3) & $24(63.2)$ & \\
\hline \multirow{2}{*}{$\begin{array}{l}\text { Smoking status after discontinuation of anti- } \\
\text { TNF therapy }\end{array}$} & Non-/ex-smoker & 104 (95.4) & $66(93.0)$ & $38(100.0)$ & 0.161 \\
\hline & Current smoker & $5(4.6)$ & $5(7.0)$ & 0 & \\
\hline \multirow[t]{2}{*}{ Previous intestinal surgery } & Yes & $18(16.5)$ & 18 (25.4) & 0 & 0.008 \\
\hline & No & $91(83.5)$ & $53(74.6)$ & $38(100.0)$ & \\
\hline \multirow[t]{2}{*}{ Indications for starting anti-TNF therapy } & Active luminal & $81(74.1)$ & $43(60.6)$ & $38(100.0)$ & $<0.001$ \\
\hline & Fistulizing & 28 (25.9) & $28(39.4)$ & 0 & \\
\hline \multirow[t]{5}{*}{ Type of anti-TNF } & Infliximab & 93 (85.3) & 62 (87.3) & $31(81.6)$ & 0.343 \\
\hline & Remicade & 86 & 59 & 27 & \\
\hline & Remsima & 7 & 3 & 4 & \\
\hline & Adalimumab & $15(13.8)$ & $9(12.7)$ & $6(15.8)$ & \\
\hline & Golimumab & $1(0.9)$ & 0 & $1(2.6)$ & \\
\hline Duration of anti-TNF treatment, mo & Median (IQR) & $12.0(9.0-26.5)$ & $12.0(10.0-24.5)$ & $12.0(8.0-32.0)$ & 0.824 \\
\hline \multicolumn{6}{|l|}{ Montreal classification } \\
\hline \multirow[t]{3}{*}{ CD: Location } & Ileum & & $10(14.1)$ & - & \\
\hline & Colonic & & $11(15.5)$ & - & \\
\hline & Ileocolonic & & $50(70.4)$ & - & \\
\hline \multirow[t]{3}{*}{ CD: Behavior } & Inflammatory & & $37(52.1)$ & - & \\
\hline & Stricturing & & 16 (22.5) & - & \\
\hline & Penetrating & & $18(25.4)$ & - & \\
\hline \multirow[t]{2}{*}{ CD: Perianal disease } & No & & $29(40.8)$ & - & \\
\hline & Yes & & $42(59.2)$ & - & \\
\hline \multirow[t]{3}{*}{ UC: Disease extent } & Proctitis & & - & 9 (23.7) & \\
\hline & Left-side & & - & 13 (34.3) & \\
\hline & Extensive & & - & $16(42.1)$ & \\
\hline \multirow[t]{9}{*}{ Reasons for discontinuation of anti-TNF therapy } & Patient's preference & $30(27.5)$ & $21(29.6)$ & 9 (23.7) & 0.006 \\
\hline & Clinician's decision & $32(29.4)$ & $18(25.4)$ & $14(36.8)$ & \\
\hline & Intolerance to adverse effects & 18 (16.5) & 7 (9.9) & $11(28.9)$ & \\
\hline & Adverse effects & 11 & 4 & 7 & \\
\hline & Opportunistic infection & 7 & 3 & 4 & \\
\hline & Others & $29(26.6)$ & 25 (35.2) & $4(10.5)$ & \\
\hline & Pregnancy/nursing & 7 & 6 & 1 & \\
\hline & Insurance/reimbursement & 17 & 17 & 0 & \\
\hline & Other factors & 5 & 2 & 3 & \\
\hline $\begin{array}{l}\text { Hemoglobin level at the time of discontinuation } \\
\text { of anti-TNF therapy, } g / d L\end{array}$ & Median (IQR) & $13.9(12.3-14.9)$ & $14.1(12.5-15.2)$ & $13.4(12.1-14.6)$ & 0.242 \\
\hline $\begin{array}{l}\text { Albumin level at the time of discontinuation of } \\
\text { anti-TNF therapy, } \mathrm{mg} / \mathrm{dL}\end{array}$ & Median (IQR) & $4.3(3.8-4.5)$ & $4.3(3.9-4.7)$ & $4.1(3.7-4.5)$ & 0.111 \\
\hline $\begin{array}{l}\mathrm{CRP} \text { at the time of discontinuation of anti-TNF } \\
\text { therapy, } \mathrm{mg} / \mathrm{dL}\end{array}$ & Median (IQR) & $0.29(0.05-0.73)$ & $0.29(0.04-0.74)$ & $0.31(0.07-0.92)$ & 0.666 \\
\hline \multirow{3}{*}{$\begin{array}{l}\text { Mucosal healing before discontinuation of anti- } \\
\text { TNF therapy }\end{array}$} & No & $19(17.4)$ & 13 (18.3) & 6 (15.8) & 0.025 \\
\hline & Yes & 34 (31.2) & 16 (22.5) & $18(47.4)$ & \\
\hline & Unknown & $56(51.4)$ & 42 (59.2) & 14 (36.8) & \\
\hline \multirow{2}{*}{$\begin{array}{l}\text { Immunomodulator use after discontinuation of } \\
\text { anti-TNF treatment }\end{array}$} & No & $44(40.4)$ & $22(31.0)$ & $22(57.9)$ & 0.006 \\
\hline & Yes & $65(59.6)$ & $49(69.0)$ & $16(42.1)$ & \\
\hline
\end{tabular}

Data are presented as number (\%).

$C D$, Crohn's disease; UC, ulcerative colitis; IQR, interquartile range; TNF, tumor necrosis factor; CRP, C-reactive protein.

*For the comparisons between CD and UC. 
issues. The mucosal healing status was assessed in approximately half of the patients before discontinuation. Among them, two-thirds achieved mucosal healing. Immunomodulator therapy was prescribed for 65 IBD patients (59.6\%) after discontinuation of ant-TNF.

\section{Characteristics of the enrolled patients and relapse rates after discontinuation of anti-TNF}

The median follow-up duration (months) after discontinuation of anti-TNF was 56.0 (34.5 to 90.0) for IBD patients, 73.0 (37.0 to 117.0) for $\mathrm{CD}$ and 42.5 (27.3 to 65.3) for UC patients. After anti-TNF cessation, relapse was noted in $69 \mathrm{IBD}$ patients (63.3\%), including $50 \mathrm{CD}(70.4 \%)$ and 19 UC (50.0\%). The cumulative relapse rates at 1,2 , 3 , and 5 years for IBD patients were $17.4 \%, 32.9 \%, 46.7 \%$, and $62.9 \%$, respectively, $11.3 \%, 31.4 \%, 46.7 \%$, and $62.5 \%$, respectively for $\mathrm{CD}$ patients. The cumulative relapse rates for UC patients, were $28.9 \%, 34.8 \%, 45.3 \%$, and $60.9 \%$, respectively (Fig. 2).

\section{Predictors of relapse after discontinuation of anti- TNF}

In $\mathrm{CD}$ patients, the multivariable Cox analysis showed that ADA use was associated with higher risk of relapse (vs IFX: hazard ratio [HR], 4.42; 95\% confidence interval, 1.24 to $17.74 ; \mathrm{p}=0.022$ ) and discontinuation of treatment owing to clinician's decision was associated with lower risk of relapse (vs patient's preference: $\mathrm{HR}, 0.13 ; 95 \%$ confidence interval, 0.04 to $0.48 ; \mathrm{p}=0.002$ ) (Table 2). The relapse-free survival curves based on the type of anti-TNF agent and reasons for discontinuation of anti-TNF in $\mathrm{CD}$ patients are shown in Fig. 3. However, for UC patients, the Cox analysis

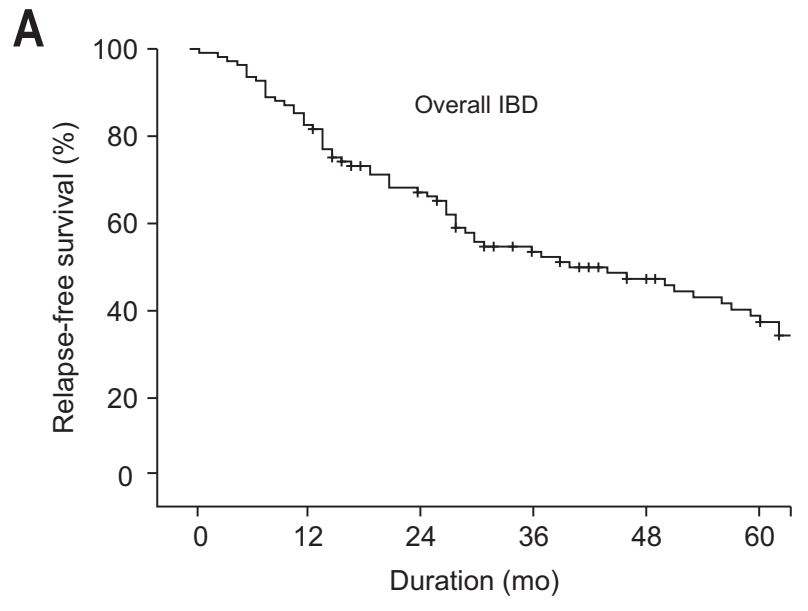

$\begin{array}{lllllll}\text { No. at risk } & 109 & 90 & 66 & 45 & 34 & 25\end{array}$ revealed that the risk of relapse was negatively associated with the mucosal healing before discontinuation of antiTNF (vs non-mucosal healing: HR, 0.12; 95\% confidence interval, 0.02 to $0.83 ; \mathrm{p}=0.031$ ) (Table 3 ). The relapse-free survival curves for mucosal healing in UC patients are shown in Fig. 4.

\section{Efficacy and safety of retreatment with anti-TNF}

After relapse, $52 \mathrm{IBD}$ patients (75.4\%; $40 \mathrm{CD}$ and $12 \mathrm{UC}$ ), underwent anti-TNF re-induction. Two patients (3.8\%) experienced anti-TNF-related infusion reactions. Fortyfour patients achieved remission, and six patients showed response to retreatment. However, anti-TNF retreatment was discontinued in $25 \mathrm{IBD}$ patients (50\%; $17 \mathrm{CD}$ and eight UC). The reasons for discontinuation were LOR for 15 patients (including three cases of intolerance); patient's preference, six patients; clinician's decision, two patients; and other factors, two patients. The median time to LOR was 60.0 months (range, 45.7 to 74.3 months). The cumulative rate of LOR during retreatment was $11.3 \%$ at 1 year, $20.6 \%$ at 2 years, $31.5 \%$ at 3 years, and $55.4 \%$ at 5 years.

The same anti-TNF agents were re-induced in $44 \mathrm{pa}$ tients; however, the anti-TNF agents were switched (IFX to ADA [n=6], or vice versa $[n=2]$ ) in eight patients. Thirtysix of 44 patients $(81.6 \%)$ in whom anti-TNF agents were same achieved clinical remission, whereas 23 of these (54.8\%) discontinued retreatment. All eight patients for whom the anti-TNF agent was switched achieved clinical remission; however, treatment was discontinued owing to patient's preference $(n=1)$ and intolerance to $\mathrm{AE}(\mathrm{n}=1$, skin eruption; same AE to first-line anti-TNF). Although there was no statistically difference $(\mathrm{p}=0.247)$, the rate of

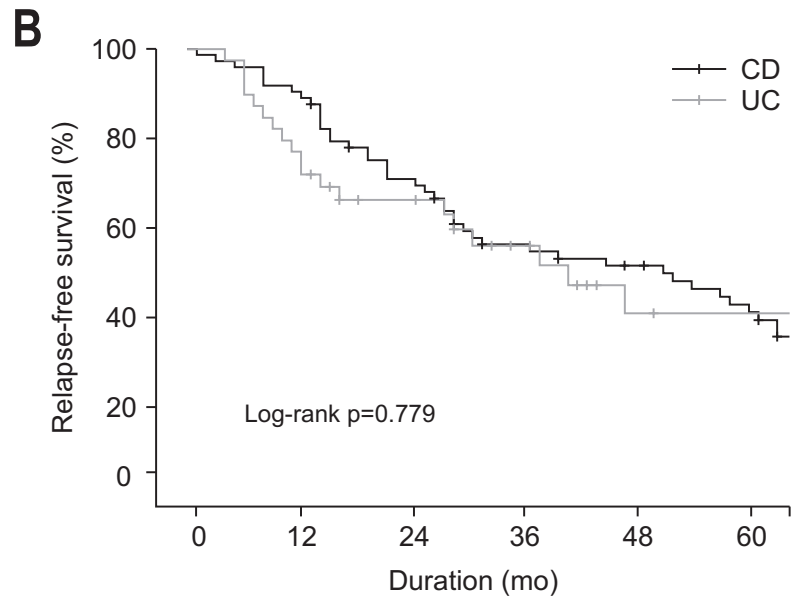

$\begin{array}{rrrrrrr}\text { No. at risk } & & & & & & \\ \text { CD } & 71 & 63 & 47 & 33 & 28 & 20 \\ \text { UC } & 38 & 27 & 19 & 12 & 10 & 5\end{array}$

Fig. 2. Relapse-free survival rates after the discontinuation of anti-tumor necrosis factor therapy. (A) Overall inflammatory bowel diseases (IBD); (B) Crohn's disease (CD) and ulcerative colitis (UC). 
Table 2. Predictors of Relapse after the Discontinuation of Anti-TNF Therapy in Patients with Crohn's Disease

\begin{tabular}{|c|c|c|c|}
\hline Characteristics & & $\mathrm{HR}(95 \% \mathrm{Cl}) *$ & p-value* \\
\hline \multirow[t]{2}{*}{ Sex } & Female & 1 & \\
\hline & Male & $0.59(0.19-1.85)$ & 0.367 \\
\hline \multirow[t]{2}{*}{ Age at diagnosis, yr } & $\leq 40$ & 1 & \\
\hline & $>40$ & $0.30(0.03-3.27)$ & 0.324 \\
\hline \multirow[t]{2}{*}{ Age at the time of discontinuation of anti-TNF therapy, yr } & $\leq 40$ & 1 & \\
\hline & $>40$ & $2.04(0.39-10.79)$ & 0.402 \\
\hline \multirow[t]{2}{*}{ Smoking status after discontinuation of anti-TNF therapy } & Non-/ex-smoker & 1 & \\
\hline & Current smoker & $0.53(0.06-4.72)$ & 0.571 \\
\hline \multirow[t]{2}{*}{ Previous intestinal surgery } & No & 1 & \\
\hline & Yes & $2.16(0.87-5.38)$ & 0.097 \\
\hline \multirow[t]{2}{*}{ Indications for initiation of anti-TNF therapy } & Active luminal & 1 & \\
\hline & Fistulizing & $0.57(0.25-1.29)$ & 0.179 \\
\hline \multirow[t]{2}{*}{ Type of anti-TNF } & Infliximab & 1 & \\
\hline & Adalimumab & $4.42(1.24-17.74)$ & 0.022 \\
\hline Duration of anti-TNF treatment, mo & & $1.01(0.98-1.03)$ & 0.704 \\
\hline \multirow[t]{2}{*}{ Montreal location } & Ileum or ileocolonic & 1 & \\
\hline & Colonic & $0.97(0.31-3.04)$ & 0.961 \\
\hline \multirow[t]{2}{*}{ Montreal behavior } & Inflammatory & 1 & \\
\hline & Stricturing or penetrating & $1.10(0.46-2.63)$ & 0.835 \\
\hline \multirow[t]{2}{*}{ Perianal disease } & No & 1 & \\
\hline & Yes & $1.49(0.62-3.55)$ & 0.372 \\
\hline \multirow[t]{4}{*}{ Reason for discontinuation of anti-TNF therapy } & Patient's preference & 1 & 0.023 \\
\hline & Clinician's decision & $0.13(0.04-0.48)$ & 0.002 \\
\hline & Intolerance to adverse effects & $0.43(0.11-1.75)$ & 0.240 \\
\hline & Others & $0.62(0.26-1.51)$ & 0.296 \\
\hline \multicolumn{2}{|l|}{ Hemoglobin level at the time of discontinuation of anti-TNF therapy, $\mathrm{g} / \mathrm{dL}$} & $0.86(0.61-1.20)$ & 0.370 \\
\hline \multicolumn{2}{|l|}{ Albumin level at the time of discontinuation of anti-TNF therapy, $\mathrm{mg} / \mathrm{dL}$} & $0.58(0.23-1.43)$ & 0.234 \\
\hline \multicolumn{2}{|l|}{ CRP level at the time of discontinuation of anti-TNF therapy, $\mathrm{mg} / \mathrm{dL}$} & $1.01(0.96-1.05)$ & 0.795 \\
\hline \multirow[t]{3}{*}{ Mucosal healing before discontinuation of anti-TNF therapy } & No & 1 & 0.865 \\
\hline & Yes & $0.84(0.21-3.37)$ & 0.804 \\
\hline & Unknown & $0.74(0.22-2.49)$ & 0.629 \\
\hline \multirow[t]{2}{*}{ Immunomodulator use after discontinuation of anti-TNF therapy } & No & 1 & \\
\hline & Yes & $0.70(0.30-1.64)$ & 0.411 \\
\hline
\end{tabular}

TNF, tumor necrosis factor; $\mathrm{HR}$, hazard ratio; $\mathrm{Cl}$, confidence interval; CRP, C-reactive protein.

*Multivariable analysis.

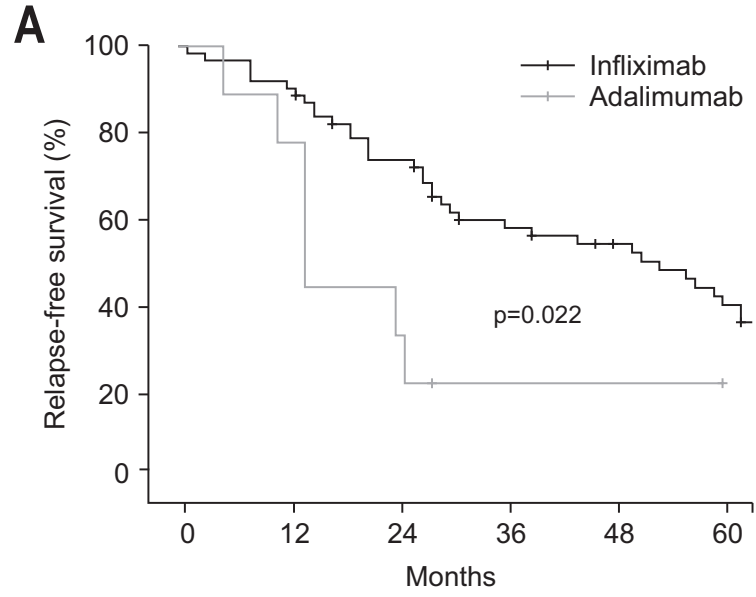

No. at risk

$\begin{array}{rrrrrrr}\longrightarrow & 62 & 61 & 57 & 50 & 42 & 38 \\ - & 9 & 8 & 7 & 4 & 3 & 1\end{array}$

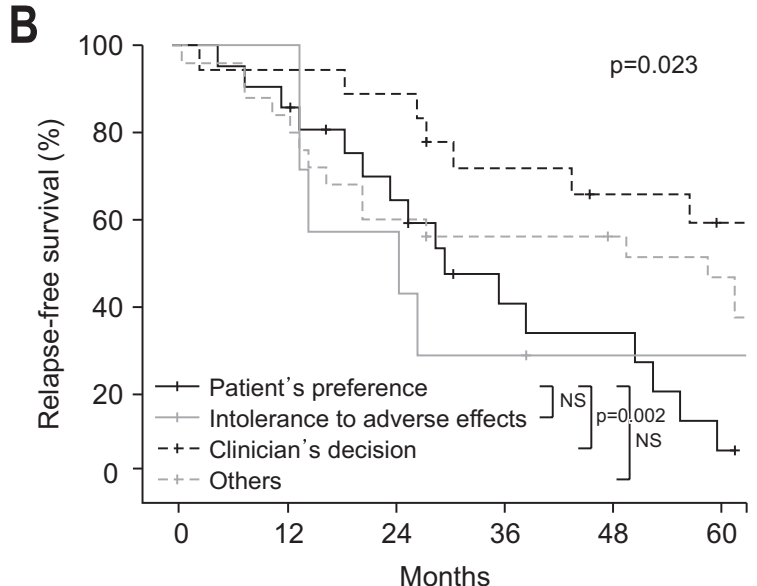

No. at risk

$\begin{array}{rrrrrrr}+ & 21 & 21 & 18 & 14 & 13 & 10 \\ +- & 7 & 7 & 5 & 4 & 3 & 3 \\ -+- & 18 & 18 & 18 & 14 & 12 & 9 \\ -+- & 25 & 25 & 23 & 22 & 18 & 17\end{array}$

Fig. 3. Relapse-free survival rates in patients with Crohn's disease after the discontinuation of anti-tumor necrosis factor (TNF) according to type of anti-TNF agent (A) and reason for the discontinuation of anti-TNF (B). 
Table 3. Predictors of Relapse after the Discontinuation of Anti-TNF Therapy in Patients with Ulcerative Colitis

\begin{tabular}{|c|c|c|c|}
\hline Characteristics & & $\operatorname{HR}(95 \% \mathrm{CI}) *$ & p-value* \\
\hline \multirow[t]{2}{*}{ Sex } & Female & 1 & \\
\hline & Male & $0.44(0.05-4.10)$ & 0.473 \\
\hline \multirow[t]{2}{*}{ Age at diagnosis, yr } & $\leq 40$ & 1 & \\
\hline & $>40$ & $0.51(0.08-3.20)$ & 0.468 \\
\hline \multirow[t]{2}{*}{ Age at the time of discontinuation of anti-TNF therapy, yr } & $\leq 40$ & 1 & \\
\hline & $>40$ & $2.46(0.39-15.60)$ & 0.339 \\
\hline \multirow[t]{2}{*}{ Type of anti-TNF } & Infliximab & 1 & \\
\hline & Adalimumab or golimumab & $0.56(0.07-4.22)$ & 0.571 \\
\hline Duration of anti-TNF treatment, mo & & $0.98(0.94-1.02)$ & 0.301 \\
\hline \multirow[t]{2}{*}{ Disease extent } & Proctitis or left side & 1 & \\
\hline & Extensive & $1.44(0.33-6.37)$ & 0.629 \\
\hline \multirow[t]{4}{*}{ Reasons for discontinuation of anti-TNF therapy } & Patient's preference & 1 & 0.594 \\
\hline & Clinician's decision & $1.65(0.30-9.05)$ & 0.566 \\
\hline & Intolerance to adverse effects & $2.27(0.24-21.86)$ & 0.480 \\
\hline & Others & $4.51(0.48-42.29)$ & 0.187 \\
\hline \multicolumn{2}{|l|}{ Hemoglobin level at the time of discontinuation of anti-TNF therapy, $\mathrm{g} / \mathrm{dL}$} & $1.52(0.73-3.17)$ & 0.266 \\
\hline \multicolumn{2}{|l|}{ Albumin level at the time of discontinuation of anti-TNF therapy, mg/dL } & $2.57(0.30-21.80)$ & 0.388 \\
\hline \multicolumn{2}{|l|}{ CRP level at the time of discontinuation of anti-TNF therapy, mg/dL } & $1.07(0.58-1.98)$ & 0.818 \\
\hline \multirow[t]{3}{*}{ Mucosal healing before discontinuation of anti-TNF therapy } & No & 1 & 0.089 \\
\hline & Yes & $0.12(0.02-0.83)$ & 0.031 \\
\hline & Unknown & $0.22(0.03-1.53)$ & 0.126 \\
\hline \multirow[t]{2}{*}{ Immunomodulator use after discontinuation of anti-TNF therapy } & No & 1 & \\
\hline & Yes & $0.61(0.18-2.04)$ & 0.418 \\
\hline
\end{tabular}

TNF, tumor necrosis factor; HR, hazard ratio; $\mathrm{Cl}$, confidence interval; CRP, C-reactive protein.

*Multivariable analysis.

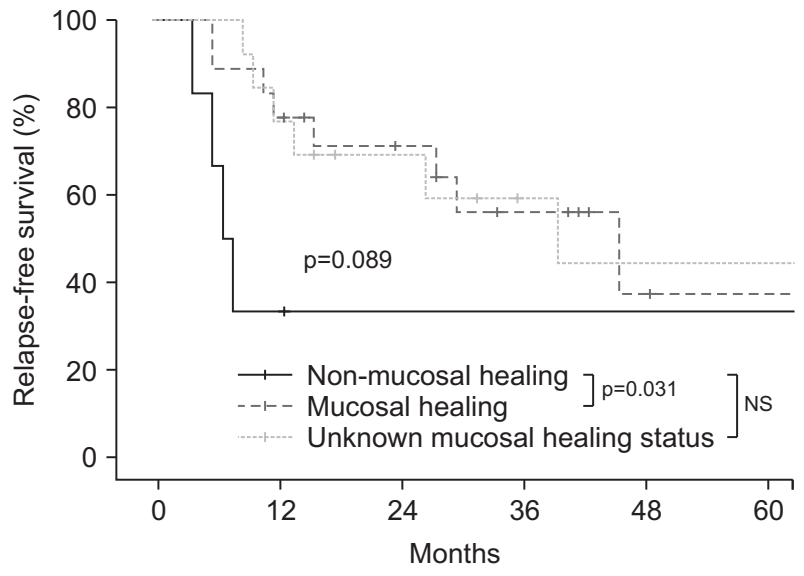

No. at risk

$\begin{array}{rrrrrrr}\longleftarrow & 6 & 6 & 5 & 5 & 3 & 2 \\ --- & 18 & 18 & 14 & 10 & 6 & 4 \\ -\cdots & 14 & 13 & 11 & 10 & 7 & 5\end{array}$

Fig. 4. Relapse-free survival rates in patients with ulcerative colitis after the discontinuation of anti-tumor necrosis factor according to the mucosal healing status.

retreatment cessation was lower in patients for whom the anti-TNF agent was switched than for those retreated with the same agent (25.0\% vs $54.8 \%)$. LOR was noted in one patient for whom the anti-TNF agent was switched.

AEs following anti-TNF retreatment were noted in six
IBD patients (11.5\%; five CD and one UC). They were newly developed, except for one CD patient. AEs included pruritis and skin eruptions. Only one patient, among them, retreated with switched anti-TNF.

\section{DISCUSSION}

After discontinuation of anti-TNF for IBD patients under remission, relapse was noted in $70.4 \%$ of $\mathrm{CD}$ and $50.0 \%$ of UC patients during 73.0 and 42.5 months, respectively. The relapse rates at 1 and 5 years for $\mathrm{CD}$ patients were $11.3 \%$ and $62.5 \%$, respectively, while those for UC patients were $28.9 \%$ and $60.9 \%$, respectively. Type of antiTNF agent and reasons for discontinuation of anti-TNF were associated with relapse in CD patients. The mucosal healing before discontinuation of anti-TNF was associated with a low risk of relapse in UC patients.

In most studies reporting on the outcomes of IBD patients after discontinuation of anti-TNF, follow-up duration was 1 to 2 years, and they reported similar relapse rates of approximately $50 \%{ }^{4,12,13,27-30} \mathrm{Few}$ studies have reported on the long-term outcomes. The follow-up duration in our study was 4.7 years (range, 2.9 to 7.5 years). In a follow-up study of the STORI trial (102 patients with follow-up of 7 years), the relapse rates for $\mathrm{CD}$ patients at 
1 year $(43.9 \%)$ and 2 years $(52.2 \%)$ were higher than our observed rates. ${ }^{13}$ In a meta-analysis, the risk of relapse in CD patients at 12 months (40\%) and at $\geq 25$ months (49\%) was also higher than our observed rates at 1 and 3 years. ${ }^{14}$ However, in a Spanish study (1,055 patients with followup of 2.4 years), the relapse rates for IBD patients at 1 year (24\%) were similar with our observed rates. ${ }^{12}$

Several studies have identified the risk factors for relapse after discontinuation of anti-TNF. The STORI trial suggested that the risk factors for relapse included male, low hemoglobin, increased C-reactive protein and fecal calprotectin levels. ${ }^{4}$ According to a Spanish study, the risk of relapse was increased by ADA use, elective discontinuation, intolerance to AEs, colonic involvement, and stricturing behavior. ${ }^{12}$ Immunomodulator treatment following discontinuation and age decreased the risk in CD patients. ${ }^{12,31}$ According to Papamichael et al., ${ }^{15}$ diagnosis of IBD at age $\geq 25$ years was associated with sustained remission. A prospective study reported that a history of biologics and dose-intensification during the 1-year of biological therapy ( $\mathrm{p}=0.011$ and $\mathrm{p}=0.024$, respectively) were associated with the need for and time to biologics re-initiation. ${ }^{30}$ We found that ADA use was associated with the risk of relapse compared with IFX use in CD patients, consistent with the findings of the Spanish study; however, our reported HR was relatively higher. ${ }^{12}$ Furthermore, both median time to relapse and follow-up duration after discontinuation were shorter for patients on ADA (14.0 and 36.0 months, respectively) than for those on IFX (39.0 and 78.5 months, respectively). The 1-year relapse rate was higher with ADA $(22.2 \%)$ than with IFX (9.7\%). The onset of action was faster for IFX than for ADA. Therefore, patients with ADA may report less deep remission compared with patients with IFX for similar treatment periods. However, this result should be interpreted carefully because as the proportion of patients treated with ADA was only $12.7 \%$, the possibility of bias cannot be disregarded; moreover, undetectable variables, which may have been associated with relapse, were not evaluated.

In $\mathrm{CD}$ patients, discontinuation of anti-TNF based on the clinician's decision was associated with a lower risk of relapse compared with the patient's preference. Discontinuation based on the clinician's recommendation was an attempt at de-escalation. The clinician evaluated the patient's disease activity, confirmed clinical/endoscopic remission, and then decided to withdraw anti-TNF. CD patients who discontinued anti-TNF on the clinician's recommendation showed a higher degree of inflammatory behavior and presented with unknown mucosal healing status compared with those who discontinued treatment for other reasons; however, statistically significant differences were not observed. In our study, we found that the risk of relapse was negatively associated with mucosal healing before the discontinuation of anti-TNF in UC patient although this observation was not validated in other studies. Even though the rate of unknown cases of mucosal healing before discontinuation was too high, patient without mucosal healing before discontinuation showed definitely higher rate of relapse after discontinuation of anti-TNF therapy than patients with mucosal healing before discontinuation. The most common reason for discontinuation of anti-TNF was clinician decision (33.9\%) in patients with unknown mucosal healing status. In clinical settings, patients were reluctant to perform endoscopy, when the reason for discontinuation of anti-TNF therapy was patient's preference or intolerance. We estimated that symptoms were completely relieved and general conditions improved in many cases of patient's preference, but we could not quantify it. We assumed that meaningful proportion of patients with unknown mucosal healing status, achieved mucosal healing, even though $51.4 \%$ of patients could not be confirmed mucosal healing. A systematic review reported that the relapse rate was lower when anti-TNF was withdrawn based on both clinical and endoscopic remission (mucosal healing) rather than clinical remission alone. ${ }^{32}$ Therefore, mucosal healing should be evaluated when considering anti-TNF cessation.

Similar to other studies, retreatment of relapsed patients with anti-TNF was effective and safe. ${ }^{12,14}$ However, LOR or intolerance was noted for a significant number of patients who responded to anti-TNF; these factors may lead to retreatment cessation. Fifty IBD patients (30\%), including $11 \mathrm{CD}$ and four UC, showed LOR and the cumulative rate of LOR during retreatment was $11.3 \%$ at 1 year, $20.6 \%$ at 2 years, $31.5 \%$ at 3 years, and $55.4 \%$ at 5 years. The median duration of retreatment was 47.0 months (range, 24.4 to 69.6 months) and cumulative rate of retreatment cessation was $69.8 \%$ during the entire follow-up period. According to study of Ben-Horin and Chowers, ${ }^{33}$ the incidence of LOR showed in the steep slope in the first year and became more gradual in ensuing years. And Casanova et al. ${ }^{34}$ revealed that the probability of achieving remission in the short term was associated with the reason for discontinuing the first anti-TNF. The rate of LOR during anti-TNF maintenance was $52.1 \%$ at 5 years in our previous study, including IBD patients with first anti-TNF treatment, in contrast to present study, composed of selected patients who achieved clinical remission and sustained good response during 12.0 months (range, 9.0 to 26.5 months) of first anti-TNF treatment. ${ }^{35}$ Considering these points, we assumed that patients analyzed in our present study, showed less incidence of LOR than patients with first 
anti-TNF treatments. To take into account the relatively high cumulative rate of LOR and discontinuation during retreatment, in the present study, despite the effectiveness and safety of retreatment, the decision for discontinuation of anti-TNF should be re-considered. It would be better that patient who achieved only clinical remission without deep remission did not cease anti-TNF.

Most patients were retreated with the same anti-TNF agent, and only eight patients were retreated with switched agent. The rate for clinical remission was higher, rate of retreatment cessation was lower, and rate of LOR during retreatment was lower for patients for whom the anti-TNF agent was switched compared to those for patients retreated with the same agent $(\mathrm{p}=0.330, \mathrm{p}=0.247$, and $\mathrm{p}=0.412$, respectively); however, the difference was not statistically significant. Therefore, switching the type of anti-TNF agent may be considered when patients are retreated with anti-TNF; this finding is consistent with previous studies. $^{34,36}$

There are several limitations. First, this study was a retrospective study. Selection bias could not be disregarded, despite adjustment for the relevant variables. Second, since our cohort only included Koreans, the generalization of our findings to IBD patients of other ethnicities is not clear. Third, therapeutic drug monitoring and anti-drug antibody were not evaluated before discontinuation, although conventional reactive therapeutic drug monitoring and anti-drug antibody were used to evaluate the efficacy of anti-TNF. Forth, the mucosal healing was assessed in approximately half of the patients before discontinuation, because of a real-world study.

In conclusion, despite the proven efficacy of anti-TNF treatment for IBD patients, some patients discontinued treatment in the real-world practice for various reasons. In this study, we identified that the 1-year relapse rate was approximately $20 \%$ lower than that expected, although about $60 \%$ of IBD patients with anti-TNF in remission, relapsed at 5 years after treatment cessation. Anti-TNF re-induction appeared to be effective and safe; however, half of the patients discontinued retreatment, and $50 \%$ of such patients discontinued retreatment owing to LOR. Therefore, before deciding on anti-TNF cessation, the type of anti-TNF agent, reason for discontinuation, and mucosal healing status should be carefully considered for IBD patients. In addition, switching the anti-TNF agent may be better for reducing the risk of LOR when patients were retreated with anti-TNF. Further prospective studies are needed to validate these findings.

\section{CONFLICTS OF INTEREST}

Y.S.K. and J.P.I. are editorial board members of the journal but were not involved in the peer reviewer selection, evaluation, or decision process of this article. No other potential conflicts of interest relevant to this article were reported.

\section{ACKNOWLEDGEMENTS}

We would like to thank all the participants and the IBD Research Group of the Korean Association for the Study of Intestinal Diseases.

\section{AUTHOR CONTRIBUTIONS}

Conception and design of the study, analysis and interpretation of data, and preparation of the manuscript: J.H.S., E.A.K. Conception and design of the study, analysis and interpretation of data and critical revision of the manuscript for important intellectual content, and final approval of the manuscript: S.K.P., S.N.H. Critical revision of the manuscript for important intellectual content, and final approval of the manuscript: Y.S.K., K.B.B., K.O.K., H.S.L., S.B.K., S.Y.S., E.M.S., J.P.I., C.H.C.

\section{ORCID}

Joo Hye Song Eun Ae Kang Soo-Kyung Park Sung Noh Hong You Sun Kim Ki Bae Bang Kyeong Ok Kim Hong Sub Lee Sang-Bum Kang Seung Yong Shin Eun Mi Song Jong Pil Im Chang Hwan Choi

https://orcid.org/0000-0001-7089-532X

https://orcid.org/0000-0002-1166-0085 https://orcid.org/0000-0003-0220-937X https://orcid.org/0000-0001-8822-9632 https://orcid.org/0000-0002-4140-3717 https://orcid.org/0000-0002-5156-3458 https://orcid.org/0000-0002-9961-9318 https://orcid.org/0000-0001-5799-7436 https://orcid.org/0000-0002-2962-0209 https://orcid.org/0000-0002-1946-7896 https://orcid.org/0000-0001-8970-2444 https://orcid.org/0000-0002-2428-1551 https://orcid.org/0000-0003-1584-0160

\section{REFERENCES}

1. Ford AC, Sandborn WJ, Khan KJ, Hanauer SB, Talley NJ, Moayyedi P. Efficacy of biological therapies in inflammatory 
bowel disease: systematic review and meta-analysis. Am J Gastroenterol 2011;106:644-659.

2. Fukuda T, Naganuma M, Kanai T. Current new challenges in the management of ulcerative colitis. Intest Res 2019;17:36-44.

3. Lichtenstein GR, Yan S, Bala M, Blank M, Sands BE. Infliximab maintenance treatment reduces hospitalizations, surgeries, and procedures in fistulizing Crohn's disease. Gastroenterology 2005;128:862-869.

4. Louis E, Mary JY, Vernier-Massouille G, et al. Maintenance of remission among patients with Crohn's disease on antimetabolite therapy after infliximab therapy is stopped. Gastroenterology 2012;142:63-70.

5. Hong SN, Kim HJ, Kim KH, Han SJ, Ahn IM, Ahn HS. Risk of incident Mycobacterium tuberculosis infection in patients with inflammatory bowel disease: a nationwide populationbased study in South Korea. Aliment Pharmacol Ther 2017;45:253-263.

6. Kirchgesner J, Lemaitre M, Carrat F, Zureik M, Carbonnel F, Dray-Spira R. Risk of serious and opportunistic infections associated with treatment of inflammatory bowel diseases. Gastroenterology 2018;155:337-346.

7. Rahier JF, Yazdanpanah Y, Colombel JF, Travis S. The European (ECCO) Consensus on infection in IBD: what does it change for the clinician? Gut 2009;58:1313-1315

8. Long MD, Martin CF, Pipkin CA, Herfarth HH, Sandler RS, Kappelman MD. Risk of melanoma and nonmelanoma skin cancer among patients with inflammatory bowel disease. Gastroenterology 2012;143:390-399.

9. Mocci G, Marzo M, Papa A, Armuzzi A, Guidi L. Dermatological adverse reactions during anti-TNF treatments: focus on inflammatory bowel disease. J Crohns Colitis 2013;7:769779.

10. van der Valk ME, Mangen MJ, Leenders M, et al. Healthcare costs of inflammatory bowel disease have shifted from hospitalisation and surgery towards anti-TNFa therapy: results from the COIN study. Gut 2014;63:72-79.

11. Ben-Horin S, Mao R, Qiu Y, Chen M. Discontinuation of biological treatments in inflammatory bowel disease: a concise pragmatic review. J Clin Gastroenterol 2018;52:6-12.

12. Casanova MJ, Chaparro M, García-Sánchez V, et al. Evolution after anti-TNF discontinuation in patients with inflammatory bowel disease: a multicenter long-term follow-up study. Am J Gastroenterol 2017;112:120-131.

13. Reenaers C, Mary JY, Nachury M, et al. Outcomes 7 years after infliximab withdrawal for patients with Crohn's disease in sustained remission. Clin Gastroenterol Hepatol 2018;16:234-243.

14. Gisbert JP, Marín AC, Chaparro M. The risk of relapse after anti-TNF discontinuation in inflammatory bowel disease: systematic review and meta-analysis. Am J Gastroenterol 2016;111:632-647.
15. Papamichael K, Vande Casteele N, Gils A, et al. Long-term outcome of patients with Crohn's disease who discontinued infliximab therapy upon clinical remission. Clin Gastroenterol Hepatol 2015;13:1103-1110.

16. Molander P, Färkkilä M, Salminen K, et al. Outcome after discontinuation of TNFa-blocking therapy in patients with inflammatory bowel disease in deep remission. Inflamm Bowel Dis 2014;20:1021-1028.

17. Clarke K, Regueiro M. Stopping immunomodulators and biologics in inflammatory bowel disease patients in remission. Inflamm Bowel Dis 2012;18:174-179.

18. Farkas K, Lakatos PL, Nagy F, et al. Predictors of relapse in patients with ulcerative colitis in remission after one-year of infliximab therapy. Scand J Gastroenterol 2013;48:13941398.

19. D'Haens GR, Panaccione R, Higgins PD, et al. The London Position Statement of the World Congress of Gastroenterology on Biological Therapy for IBD with the European Crohn's and Colitis Organization: when to start, when to stop, which drug to choose, and how to predict response? Am J Gastroenterol 2011;106:199-212.

20. Dignass A, Van Assche G, Lindsay JO, et al. The second European evidence-based consensus on the diagnosis and management of Crohn's disease: current management. J Crohns Colitis 2010;4:28-62.

21. Dignass A, Lindsay JO, Sturm A, et al. Second European evidence-based consensus on the diagnosis and management of ulcerative colitis part 2: current management. J Crohns Colitis 2012;6:991-1030.

22. Hanauer SB, Feagan BG, Lichtenstein GR, et al. Maintenance infliximab for Crohn's disease: the ACCENT I randomised trial. Lancet 2002;359:1541-1549.

23. Colombel JF, Sandborn WJ, Reinisch W, et al. Infliximab, azathioprine, or combination therapy for Crohn's disease. $\mathrm{N}$ Engl J Med 2010;362:1383-1395.

24. Colombel JF, Sandborn WJ, Rutgeerts P, et al. Adalimumab for maintenance of clinical response and remission in patients with Crohn's disease: the CHARM trial. Gastroenterology 2007;132:52-65.

25. Roda G, Jharap B, Neeraj N, Colombel JF. Loss of response to anti-TNFs: definition, epidemiology, and management. Clin Transl Gastroenterol 2016;7:e135.

26. Kopylov U, Ben-Horin S, Seidman E. Therapeutic drug monitoring in inflammatory bowel disease. Ann Gastroenterol 2014;27:304-312.

27. Torres J, Boyapati RK, Kennedy NA, Louis E, Colombel JF, Satsangi J. Systematic review of effects of withdrawal of immunomodulators or biologic agents from patients with inflammatory bowel disease. Gastroenterology 2015;149:17161730.

28. Bortlik M, Duricova D, Machkova N, et al. Discontinuation 
of anti-tumor necrosis factor therapy in inflammatory bowel disease patients: a prospective observation. Scand J Gastroenterol 2016;51:196-202.

29. Steenholdt C, Molazahi A, Ainsworth MA, Brynskov J, Østergaard Thomsen O, Seidelin JB. Outcome after discontinuation of infliximab in patients with inflammatory bowel disease in clinical remission: an observational Danish single center study. Scand J Gastroenterol 2012;47:518-527.

30. Molnár T, Lakatos PL, Farkas K, et al. Predictors of relapse in patients with Crohn's disease in remission after 1 year of biological therapy. Aliment Pharmacol Ther 2013;37:225-233.

31. Ooi CJ, Hilmi I, Banerjee R, et al. Best practices on immunomodulators and biologic agents for ulcerative colitis and Crohn's disease in Asia. Intest Res 2019;17:285-310.

32. Gisbert JP, Marín AC, Chaparro M. Systematic review: factors associated with relapse of inflammatory bowel disease after discontinuation of anti-TNF therapy. Aliment Pharmacol Ther 2015;42:391-405.
33. Ben-Horin S, Chowers Y. Review article: loss of response to anti-TNF treatments in Crohn's disease. Aliment Pharmacol Ther 2011;33:987-995.

34. Casanova MJ, Chaparro M, Mínguez M, et al. Effectiveness and safety of the sequential use of a second and third anti-TNF agent in patients with inflammatory bowel disease: results from the Eneida Registry. Inflamm Bowel Dis 2020;26:606-616.

35. Song JH, Hong SN, Lee JE, et al. C-reactive protein reduction rate following initiation of anti-tumor necrosis factor a induction therapy predicts secondary loss of response in patients with Crohn's disease. Scand J Gastroenterol 2019;54:876-885.

36. Gisbert JP, Marín AC, McNicholl AG, Chaparro M. Systematic review with meta-analysis: the efficacy of a second antiTNF in patients with inflammatory bowel disease whose previous anti-TNF treatment has failed. Aliment Pharmacol Ther 2015;41:613-623. 